\title{
Expression of $\mathrm{CXC}$-motif-chemokine 12 and the receptor $\mathrm{C}-\mathrm{X}-\mathrm{C}$ receptor 4 in glioma and theeffect on peritumoral brain edema
}

\author{
WENLONG TANG ${ }^{1}$, YUPENG CHEN ${ }^{2}$, XINGFU WANG ${ }^{2}$, YAO CHEN ${ }^{1}$, JIANDONG ZHANG $^{1}$ and ZHIXIONG LIN ${ }^{1,3}$ \\ Departments of ${ }^{1}$ Neurosurgery and ${ }^{2}$ Pathology, The First Affiliated Hospital of \\ Fujian Medical University, Fuzhou, Fujian 350005; ${ }^{3}$ Department of Neurosurgery, \\ Beijing Sanbo Brain Hospital, Capital Medical University, Beijing 100093, P.R. China
}

Received October 8, 2015; Accepted March 21, 2017

DOI: $10.3892 / \mathrm{ol} .2017 .7547$

\begin{abstract}
The present study aimed to evaluate the association between CXC-motif-chemokine 12 (CXCL12)/C-X-C receptor 4 (CXCR4) expression and peritumoral brain edema (PTBE) in glioma patients. Immunohistochemical techniques were used to detect the expression of CXCR4 and CXCL12 in 58 glioma tissues. Magnetic resonance imaging was used to evaluate the extent and type of brain edema in preoperative glioma patients. The association between edema and CXCL12/CXCR4 expression was examined by $\chi^{2}$ analysis. The prognostic significance of CXCL12 or CXCR4 was determined by log-rank tests and Cox's proportional hazards model. Expression of CXCL12 and CXCR4 was observed in vascular endothelial cells and tumor cells. The degree $(\mathrm{P}=0.033)$ and morphology $(\mathrm{P}=0.033)$ of PTBE were significantly associated with the level of CXCL12 expression in vascular endothelial cells. The degree $(\mathrm{P}=0.001)$ and morphology $(\mathrm{P}=0.001)$ of PTBE were associated with the level of CXCR4 expression in tumor cells. CXCR4-positive vascular endothelial cells were significantly associated only with the degree of edema $(\mathrm{P}=0.030)$. Therefore, the present study indicated that levels of CXCL12 expression in vascular endothelial cells and CXCR4 expression in tumor cells are associated with PTBE.
\end{abstract}

\section{Introduction}

Glioma, which is the most common intracranial tumor in adults, is characterized by high vascularization and invasive capacity, as well as peritumoral brain edema (PTBE) (1-4). In preoperative magnetic resonance imaging (MRI), the degree and morphological characteristics of PTBE vary between different

Correspondence to: $\mathrm{Dr}$ Zhixiong Lin, Department of Neurosurgery, Beijing Sanbo Brain Hospital, Capital Medical University, 50 Xiangshang Road, Beijing 100093, P.R. China E-mail: 1zx1967@sina.com

Keywords: CXC-motif-chemokine 12,C-X-C receptor 4,peritumoral brain edema, glioma types of glioma (5). PTBE, which facilitates glioma cell invasion and significantly affects patient prognosis, is a major cause of the high disability and mortality rate of glioma $(4,6)$. A previous study has demonstrated that glioma recurrence patterns are affected by the degree and morphological characteristics of PTBE (7). In addition, a study has identified that PTBE is an imaging feature of glioma cell invasion, a complex process regulated by specific signaling pathways (8). Previous studies have shown that the cell surface $\mathrm{C}-\mathrm{X}-\mathrm{C}$ receptor 4 (CXCR4), and its protein ligand, CXC-motif-chemokine 12 (CXCL12), are overexpressed in glioma tissues (9-11). The CXCR4-CXCL12 signaling pathway regulates glioma cell differentiation, invasion and metastasis $(12,13)$. According to the law of tissue remodeling presented by Lin (14), tissue morphology is the result of the interactions among molecules within the tumor microenvironment. It was hypothesized that the CXCR4-CXCL12 signaling pathway affects the degree and morphological characteristics of PTBE. To the best of our knowledge, there are currently no studies describing the association between the CXCR4-CXCL12 axis and PTBE in glioma patients. Therefore, the present study investigated the association between CXCR4/CXCL12 and PTBE in glioma tissues.

\section{Materials and methods}

Study samples. The clinicopathological data of patients with supratentorial glioma ( $n=58 ; 41$ male, 17 female) treated at the First Affiliated Hospital of Fujian Medical University (Fujian, China) between December 2007 and April 2014 were collected retrospectively. The median age was $44.57 \pm 13.90$ years (range, 17-75 years). The pathological diagnosis of each patient was confirmed by neuropathologists based on the brain tumor pathology classification standard of 2007 (15). All patients received postoperative chemoradiotherapy. Chemotherapy (at least four cycles) with temozolomide was administered at a dose of 150-200 mg/m²/day. Radiotherapy (60 Gy in 2 Gy fractions) was applied to the field of the tumor lesion plus a $2 \mathrm{~cm}$ margin, according to MRI at the time of the second chemotherapy cycle. The present study was approved by the Ethics Committee of Fujian Medical University (Fuzhou, China), and all enrolled patients provided written informed consent for inclusion in the present study. 
Immunohistochemistry. Glioma and adjacent non-tumor tissue acquired during surgery from the patients described previously were embedded in paraffin immediately and sectioned to $5 \mu \mathrm{m}$ using a microtome. Sections were mounted on glass slides, dew axed and hydrated for immunohistochemistry. For CXCL12 and CXCR4, heat-induced epitope retrieval was performed by boiling the tissue sections in $10 \mathrm{mmol} / \mathrm{l}$ citrate buffer (pH 6.0) for $15 \mathrm{~min}$ in a microwave oven. Subsequent to cooling to room temperature, the sections were exposed to methanol containing $3 \%$ hydrogen peroxide for $10 \mathrm{~min}$ at room temperature to block endogenous peroxidase. CXCL12 was detected with an anti-human CXCL12 monoclonal antibody (5 $\mu \mathrm{g} / \mathrm{ml}$; cat. no. MAB350; R\&D Systems, Inc., Minneapolis, MN, USA) for $1 \mathrm{~h}$ at room temperature. CXCR4 was detected with an anti-human CXCR4 monoclonal antibody $(0.5 \mu \mathrm{g} / \mathrm{ml}$; cat. no. MAB172, R\&D Systems, Inc.) for $1 \mathrm{~h}$ at room temperature. The slides were then washed with PBS and incubated with the secondary detection antibody, polyperoxidase-anti-rabbit/mouse IgG (dilution, 1:1,000; cat. no. C0101, ZSGB-BIO, Beijing, China) for $50 \mathrm{~min}$ at room temperature. Then the slides were treated with with diaminobenzidine (dilution, 1:1,000; cat. no. 070004; Cell Chip Biotechnology Co., Beijing, China) as per the manufacturer's protocol. The sections were counterstained with hematoxylin and mounted in gelatin. Gastric cancer and tonsil tissues were used as positive controls for CXCR4 and CXCL12 expression, respectively. Gastric cancer tissues were acquired from a patient with postoperative pathological diagnosis of gastric carcinoma. Tonsil tissues were acquired from a normal control. PBS was substituted for the primary antibodies as a negative control.

Histological assessment. Immunohistochemical staining of five randomly selected fields for each tumor specimen was evaluated under a light microscope (magnification, x200) and classified according to the method proposed by Zagzag et al (16): Low expression, staining $<5 \%$ of structures; high expression, staining of $>5 \%$ of structures. The results were evaluated independently by two pathologists. In cases of discordance, a third pathologist reviewed the results to achieve a consensus.

Imaging methodology and analyses. Preoperative MRI scans [T1 weighted image (T1WI), T2 weighted image (T2WI), axes, arrows and coronal enhanced images] were performed at the First Affiliated Hospital of Fujian Medical University. The boundaries of the contrast enhancement area on T1 weighted images were drawn. These maps were then compared with their respective T2 weighted images. According to Schoenegger et al (2), PTBE was classified according to degree as follows: Minor, edema extending $\leq 1 \mathrm{~cm}$ from the tumor margin (Fig. 1A and B) and major, edema extending $>1 \mathrm{~cm}$ from the tumor margin (Fig. $1 \mathrm{C}$ and D). According to Hartmann et al (7), the PTBE morphology types were classified as: Ring form, circular region of increased T2 signal intensity (Fig. 1A and B); and irregular form, irregular regions of increased T2 signal intensity (Fig. 1C and D). Based on these definitions, PTBE types and degrees on preoperative MR images were classified by two experienced imageologists. Discrepancies in the classification were reviewed by a third imageologist until a consensus was achieved.
Analysis. Each patient was followed-up in outpatient visits or telephone conversations. The median progression-free survival time (PFS, months) was calculated from the date of surgery to the date of first tumor progression (or mortality or the latest follow-up). The overall survival (OS, months) time was defined as the period from the time of surgical resection to the latest follow-up (or mortality). PFS and OS times for patients without tumor progression or mortality ended with the latest follow-up.

Statistical analysis. Statistical analysis was performed with SPSS 19.0 for Windows (IBM SPSS, Armonk, NY, USA). The associations between age, sex, pathological grade, morphological types of PTBE, degrees of PTBE and CXCR4/CXCL12 expression levels were initially examined by $\chi^{2}$ analysis or Fisher's exact test. Non-parametric tests were used to analyze the association between pathological grades and expression levels of CXCL12 or CXCR4. The associations between PFS and OS and CXCL12/CXCR4 expression levels were determined by log-rank tests and presented as Kaplan-Meier curves. In multivariate analyses, the COX proportional hazards model was adopted to assess the effects of CXCL12/CXCR4 expression levels on PFS and OS. In addition, hazard ratios as well as the corresponding $95 \%$ confidence intervals were calculated. $\mathrm{P}<0.05$ was considered to indicate a statistically significant difference.

\section{Results}

CXCL12 and CXCR4 expression in glioma tissues. Immunohistochemical staining demonstrated that CXCL12 and CXCR4 were located in the cell membrane and cytoplasm. Widespread staining of CXCL12, but not CXCR4, was also observed in adjacent normal brain tissues. In the 58 glioma tissue samples, CXCL12 expression was observed mainly in the vascular endothelial cells, with low levels of expression also observed in tumor cells. CXCL12 positive staining was detected in 52/58 glioma specimens. In vascular endothelial cells, CXCL12 expression was detected in glomeruloid vessels (Fig. 2A) and non-glomeruloid vessels (Fig. 2B), with low expression identified in 26 and high expression in 32 glioma tissue samples. In addition, CXCL12-positive endothelial cells were particularly high expression in areas of tumor adjacent to necrosis (Fig. 2C). In tumor cells (Fig. 2D), low CXCL12 expression was detected in 49 samples and high expression in 9 samples.

CXCR4 expression was detected in 52/58 glioma tissues, mainly in tumor cells (Fig. 2E and F), with particularly high expression in areas of tumor adjacent to necrosis (Fig. 2G). In addition, CXCR4 with low levels of expression also observed in vascular endothelial cells (Fig. 2H). Low CXCR4 expression in tumor cells was detected in 19 samples and high expression was detected in 39 samples. In vascular endothelial cells, low expression was detected in 36 samples and high expression was detected in 22 samples.

Notably, in tumor cells with high CXCR4 expression, the expression of CXCL12 in vascular endothelial cells was also high in the same specimens. It was also revealed that CXCR4 was highly expressed in tumor cells, and CXCL12 was lowly expressed in tumor cells in the same tissue. Similarly, in 


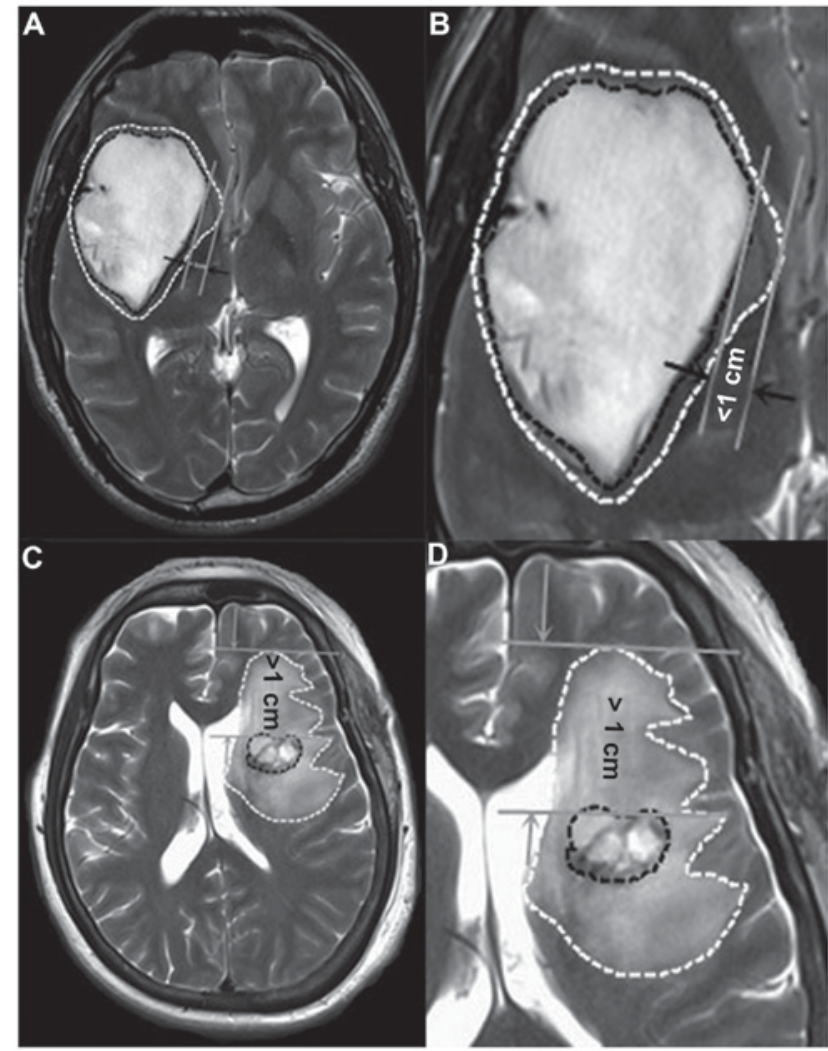

Figure 1. Measurement of peritumoral edema in magnetic resonance imaging T2 weighted images. (A) Circular edema extending $<1 \mathrm{~cm}$ from the tumor margin, defined as minor edema in ring form. (B) Image A at x10 magnification. (C) Irregular edema extending $>1 \mathrm{~cm}$ from the tumor margin, defined as major edema in irregular form. (D) Image $\mathrm{C}$ at x10 magnification.

vascular endothelial cells, high CXCL12 expression was associated with low CXCR4 expression in tumor cells.

Association between CXCL12 and CXCR4 expression and clinicopathological features. The associations between CXCL12 expression and clinicopathological features are listed in Table I. CXCL12 expression in vascular endothelial cells was significantly associated with age $(\mathrm{P}<0.0001)$ and pathological grade $(\mathrm{P}<0.0001)$, while the level of CXCL12-positive tumor cells was significantly associated only with pathological grade $(\mathrm{P}=0.003)$. However, no association was observed between patient sex and CXCL12 expression in endothelial or tumor cells.

CXCR4 expression in tumor cells was significantly associated with age $(\mathrm{P}=0.002)$ and pathological grade $(\mathrm{P}<0.0001)$. The level of CXCR4-positive vascular endothelial cells was also significantly associated with age $(\mathrm{P}=0.016)$ and pathological grade $(\mathrm{P}<0.0001)$. However, $\mathrm{CXCR} 4$ expression was not associated with patient sex in tumor or endothelial cells (Table II).

Association between CXCL12 and CXCR4 expression and $P T B E$. PTBE is one of the most important features of gliomas on preoperative MRI; therefore, the association between CXCL12 and CXCR4 expression and PTBE in gliomas was investigated. CXCL12 expression in vascular endothelial cells was significantly associated with edema degree $(\mathrm{P}=0.033)$ and edema morphology $(\mathrm{P}=0.033)$, while the level of

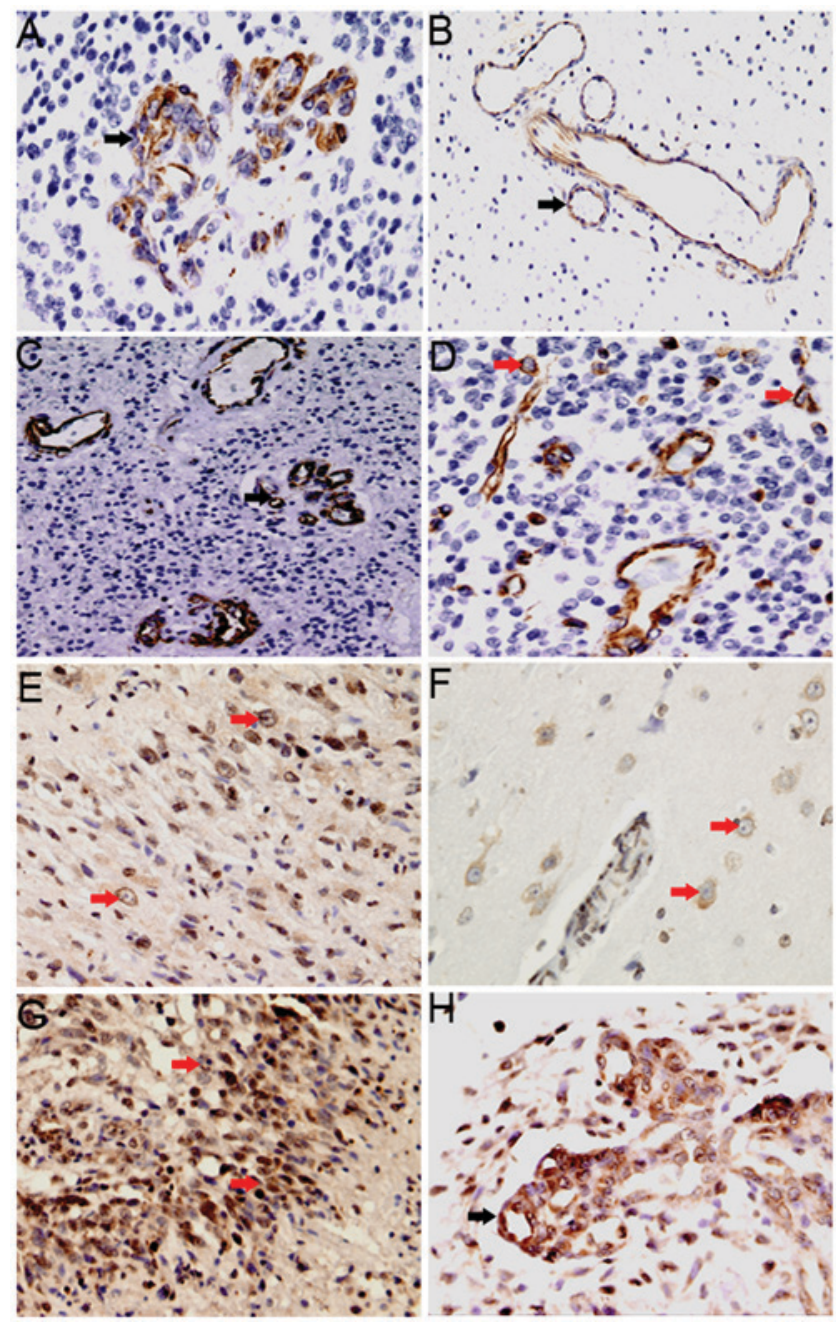

Figure 2. Degree and cellular distribution of CXCL12 and CXCR4 expression in glioma tissues. (A-D) CXCL12 expression in vascular endothelial cells (black arrow) and in tumor cells (red arrow). (A) CXCL12 expression in glomeruloid vessels (magnification, x200). (B) CXCL12 expression in the non-glomerular vessels of the peritumoral edema area (magnification, x200). (C) CXCL12 is expressed in vascular endothelial cells of the surrounding necrotic area (magnification, $x 200$ ). (D) CXCL12 expression in tumor cells (magnification, x200). (E-H) CXCR4 expression in tumor cells (red arrow) and endothelial cells (black arrows). (E) CXCR4 expression in tumor cells (magnification, x200). (F) CXCR4 expression in perivascular tumor cells of the peritumoral edema area (magnification, 400). (G) CXCR4 expression in tumor cells in the surrounding necrotic area (magnification, x200). (H) CXCR4 expression in glomeruloid vessels (magnification, x200). CXCR4, C-X-C receptor 4; CXCL12, CXC-motif-chemokine 12.

CXCL12-positive tumor cells was not significantly associated with edema degree $(\mathrm{P}=0.067)$ or morphology $(\mathrm{P}=0.167$; Table I).

For CXCR4, the degree $(\mathrm{P}=0.001)$ and morphology $(\mathrm{P}=0.001)$ of $\mathrm{PTBE}$ were positively-associated with the expression of CXCR4 in tumor cells. The level of CXCR4-positive vascular endothelial cells was significantly associated with edema degree $(\mathrm{P}=0.030)$, while no association was observed between edema morphology and CXCR4 expression in vascular endothelial cells ( $\mathrm{P}=0.106$; Table II).

Association between CXCL12 and CXCR4 expression and patient clinical outcome. To investigate the association between CXCL12 and CXCR4 expression and patient prognosis, 
Table I. Association between CXCL12 and characteristics of patients.

\begin{tabular}{|c|c|c|c|c|c|c|}
\hline \multirow[b]{2}{*}{ Patients features } & \multicolumn{2}{|c|}{$\begin{array}{c}\text { Tumoral } \\
\text { CXCL12, n }\end{array}$} & \multirow[b]{2}{*}{ P-value } & \multicolumn{2}{|c|}{$\begin{array}{l}\text { Endothelial } \\
\text { CXCL12, n }\end{array}$} & \multirow[b]{2}{*}{ P-value } \\
\hline & Low & High & & Low & High & \\
\hline Age & & & 0.473 & & & $<0.0001$ \\
\hline$<44.57$ years & 25 & 3 & & 20 & 8 & \\
\hline$\geq 44.57$ years & 24 & 6 & & 6 & 24 & \\
\hline Gender & & & 0.426 & & & 0.778 \\
\hline Male & 36 & 5 & & 19 & 22 & \\
\hline Female & 13 & 4 & & 7 & 10 & \\
\hline Pathological grade & & & 0.003 & & & $<0.0001$ \\
\hline II & 19 & 1 & & 16 & 4 & \\
\hline III & 16 & 0 & & 8 & 8 & \\
\hline IV & 14 & 8 & & 2 & 20 & \\
\hline Edema degree & & & 0.067 & & & 0.033 \\
\hline Slight & 23 & 1 & & 15 & 9 & \\
\hline Severe & 26 & 8 & & 11 & 23 & \\
\hline Edema morphology & & & 0.167 & & & 0.033 \\
\hline Ring form & 24 & 2 & & 16 & 10 & \\
\hline Irregular form & 25 & 7 & & 10 & 22 & \\
\hline
\end{tabular}

Table II. Association between CXCR4 and characteristics of patients.

\begin{tabular}{|c|c|c|c|c|c|c|}
\hline \multirow[b]{2}{*}{ Patients features } & \multicolumn{2}{|c|}{$\begin{array}{c}\text { Tumoral } \\
\text { CXCL12, n }\end{array}$} & \multirow[b]{2}{*}{ P-value } & \multicolumn{2}{|c|}{$\begin{array}{l}\text { Endothelial } \\
\text { CXCL12, n }\end{array}$} & \multirow[b]{2}{*}{ P-value } \\
\hline & Low & High & & Low & High & \\
\hline Age & & & 0.002 & & & 0.016 \\
\hline$<44.57$ years & 15 & 13 & & 22 & 6 & \\
\hline$\geq 44.57$ years & 4 & 26 & & 14 & 16 & \\
\hline Gender & & & 1.000 & & & 0.773 \\
\hline Male & 14 & 27 & & 26 & 15 & \\
\hline Female & 5 & 12 & & 10 & 7 & \\
\hline Pathological grade & & & $<0.0001$ & & & $<0.0001$ \\
\hline II & 13 & 7 & & 19 & 1 & \\
\hline III & 4 & 12 & & 9 & 7 & \\
\hline IV & 2 & 20 & & 8 & 14 & \\
\hline Edema degree & & & 0.001 & & & 0.030 \\
\hline Slight & 14 & 10 & & 19 & 5 & \\
\hline Severe & 5 & 29 & & 17 & 17 & \\
\hline Edema morphology & & & 0.001 & & & 0.106 \\
\hline Ring form & 14 & 12 & & 19 & 7 & \\
\hline Irregular form & 4 & 28 & & 16 & 16 & \\
\hline
\end{tabular}

CXCR4, C-X-C receptor 4. P-values were calculated with $\chi^{2}$ analysis.

corresponding PFS and OS were calculated from the study patients (Table III). The medianPFS was 18.12 months (range, 1-50 months) and the median OS was 25.33 months (range, 2-58 months). It was identified that high CXCL12 expression in tumor cells in 
Table III. Cox proportional hazards regressions for PFS and OS in gliomas.

\begin{tabular}{|c|c|c|c|c|}
\hline \multirow[b]{2}{*}{ Variables } & \multicolumn{2}{|c|}{ PFS } & \multicolumn{2}{|c|}{ OS } \\
\hline & $\mathrm{HR}(95 \% \mathrm{CI})$ & P-value & $\mathrm{HR}(95 \% \mathrm{CI})$ & P-value \\
\hline Age ( $\geq 44.57$ vs. $<44.57$ years $)$ & $1.14(0.46-2.84)$ & 0.772 & $2.46(0.80-7.59)$ & 0.851 \\
\hline Gender (male vs. female) & $1.66(0.69-4.02)$ & 0.258 & $1.11(0.37-3.31)$ & 0.119 \\
\hline Pathological grade (II vs. III vs. IV) & $3.77(1.88-7.58)$ & $<0.0001$ & $2.98(1.12-7.49)$ & 0.020 \\
\hline Edema (slight vs. severe) & $12.66(1.96-81.20)$ & 0.007 & $0.50(0.05-5.32$ & 0.564 \\
\hline Edema (ring form vs. irregular form) & $0.16(0.03-0.84)$ & 0.030 & $3.43(0.37-31.95)$ & 0.278 \\
\hline CXCL12 expression in TC (high vs. low) & $1.90(0.75-4.95)$ & 0.172 & $0.41(0.11-1.51)$ & 0.181 \\
\hline CXCL12 expression in EC (high vs. low) & $0.85(0.34-2.12)$ & 0.719 & $3.15(0.96-10.31)$ & 0.058 \\
\hline CXCR4 expression in TC (high vs. low) & $0.69(0.26-1.84)$ & 0.460 & $1.72(0.47-6.27)$ & 0.414 \\
\hline CXCR4 expression in EC (high vs. low) & $0.74(0.30-1.82)$ & 0.513 & $0.47(0.11-2.07)$ & 0.315 \\
\hline
\end{tabular}

PFS, progression-free survival; OS, overall survival; HR, hazard ratio; CI, confidence interval; CXCL12, CXC-motif-chemokine 12; CXCR4, C-X-C receptor 4; TC, tumor cell; EC, endothelial cell.
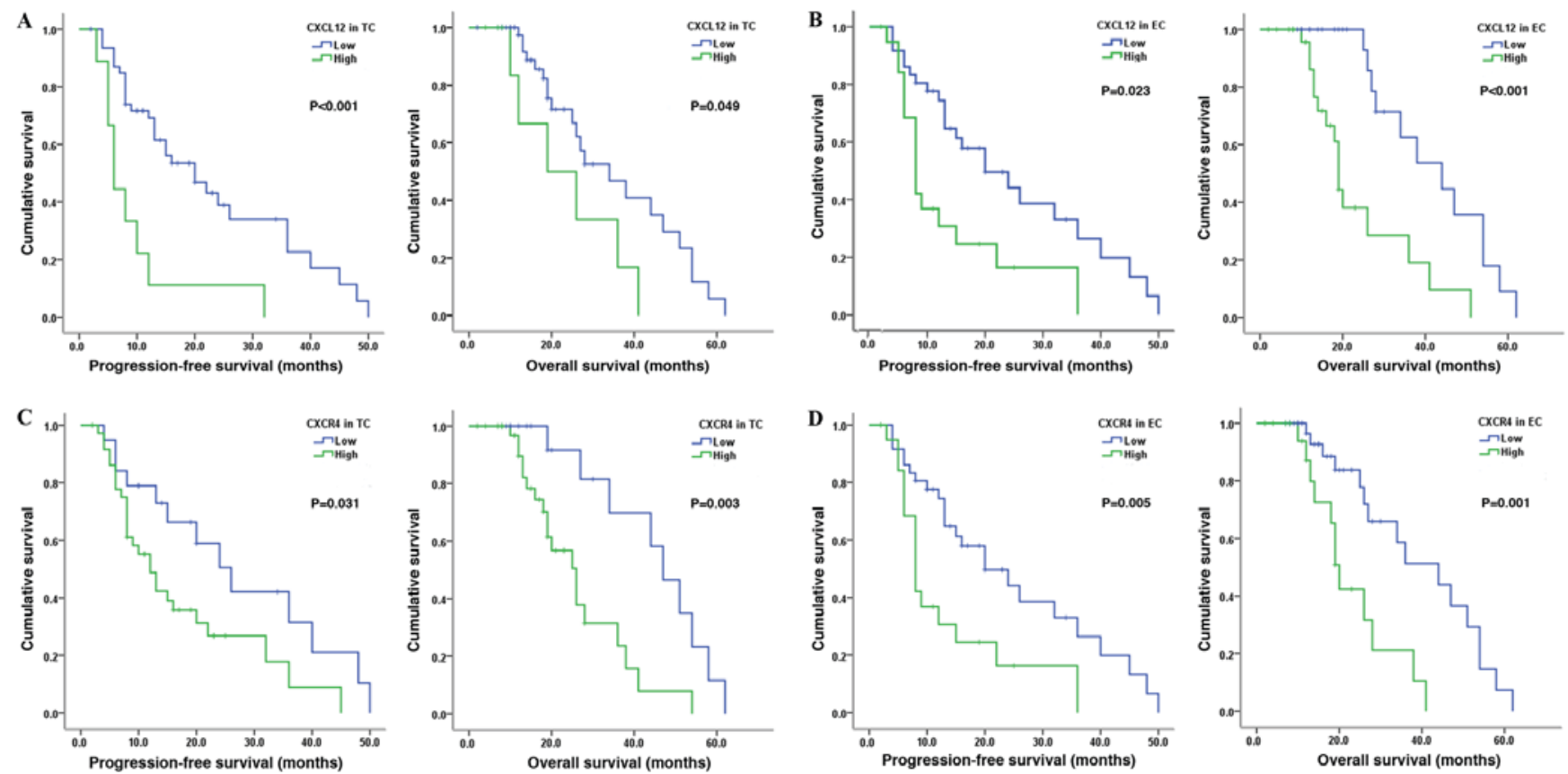

Figure 3. CXCL12 and CXCR4 expression affects PFS and OS in patients with glioma. Kaplan-Meier plots showing an association between CXCL12 expression and PFS and OS in (A) tumor cells and (B) endothelial cells. Kaplan-Meier plots showing an association between CXCR4 expression and PFS and OS in (C) tumor cells and (D) endothelial cells. TC, tumor cells; EC, endothelial cells; PFS, progression-free survival; OS, overall survival; CXCR4, C-X-C receptor 4; CXCL12, CXC-motif-chemokine 12.

patients with glioma was associated with reduced PFS $(\mathrm{P}<0.001)$ and $\mathrm{OS}(\mathrm{P}=0.049$; Fig. 3A). Similar results were observed in patients with high CXCL12 expression in vascular endothelial cells (PFS, $\mathrm{P}=0.023$; OS, $\mathrm{P}<0.001$; Fig. 3B). For $\mathrm{CXCR} 4$, the PFS $(\mathrm{P}=0.031)$ and the OS $(\mathrm{P}=0.003)$ were short in patients with high CXCR4 expression in tumor cells (Fig. 3C). Furthermore, a similar association between high CXCR4 expression in vascular endothelial cells and short PFS $(\mathrm{P}=0.005)$ and $\mathrm{OS}(\mathrm{P}=0.001)$ times was observed (Fig. 3D). Multivariate analysis showed that, regardless of the level or site of expression, CXCL12 and CXCR4 were not independent prognostic factors in patients with glioma; only pathological grade was found to be an independent prognostic factor.

\section{Discussion}

PTBE is a type of vasogenic edema, which results from interactions among cytokines secreted by nests of tumor and endothelial cells (6). CXCR4 is an a chemokine G-protein coupled receptor with seven-transmembrane alpha helices and 352 residues (17). The associated ligand CXCL12, also termed stromal-derived factor-1a, has long been known to regulate lymphocyte chemotaxis and the development of lymphoid organ structure (18). The binding of CXCR4 and CXCL12 activates downstream signaling molecules, including extracellular signal-regulated kinase-1/2, mitogen-activated protein kinase, protein kinase B/phosphoinositide 3-kinase, nuclear 
factor- $\kappa \mathrm{B}$ and c-Jun $\mathrm{N}$-terminal kinase, which promote the differentiation and invasion of tumor cells (19-22). In addition, activation of the CXCL12-CXCR4signaling pathway induces angiogenesis in glioma $(23,24)$, and blockade of this pathway has been demonstrated to reduce the density of tumor angiogenesis $(25,26)$. Therefore, the CXCR4-CXCL12 signaling pathway may affect the degree and morphological characteristics of PTBE.

In the present study, immunohistochemical staining demonstrated that CXCL12 was expressed mainly in vascular endothelial cells, while CXCR4 was mainly expressed in tumor cells, with particularly strong staining around the necrotic area. The degree and form of PTBE reflected the expression levels of CXCL12 in vascular endothelial cells and CXCR4 in tumor cells. In addition, CXCL12-positive endothelial cells were observed at the site of peritumoral edema and CXCR4-positive tumor cells were detected within the area of peritumoral edema or perivascular regions. These results indicated that the expression levels of CXCL12 in vascular endothelial cells and CXCR4 in tumor cells are associated with PTBE.

In addition, the association between CXCL12/CXCR4 expression and clinicopathological features was analyzed. Previous studies in patients with glioma have revealed an association between CXCR4 and clinicopathological features or patient survival time $(10,27)$. In the present study, it was found that age was associated with CXCR4 expression in tumor cells and vascular endothelial cells. However, only patient age was associated with CXCL12 expression in vascular endothelial cells. These data are consistent with the observation by Schoenegger et al (2) that the incidence of PTBE is associated with patient age. In the present study, CXCL12/CXCR4 expression in tumor cells and vascular endothelial cells was associated with pathological grade. In addition, Kaplan-Meier survival curve analysis revealed significantly shorter PFS and OS for patients with high CXCL12 and CXCR4 expression in tumor cells and/or endothelial cells. However, multivariate analysis found that CXCL12 and CXCR4 expression in tumor and endothelial cells were not independent prognostic factors for patients with glioblastoma.

In summary, the present data indicated that the expression levels of CXCL12 in vascular endothelial cells and CXCR4 expression in tumor cells are associated with the degree and morphological characteristics of PTBE, while CXCL12/CXCR4 expression is not an independent prognostic factor for glioma patients. However, it should be noted that the present study is subject to the limitations of a retrospective study design, potentially inaccurate data collection that relied on patient memory and a small sample size. Large-scale randomized multicenter studies are required to analyze the function of the CXCL12-CXCR4 signaling pathway in patients with glioma.

\section{Acknowledgements}

The authors would like to thank the Department of Pathology, the First Affiliated Hospital of Fujian Medical University (Fuzhou, China) for help in immunohistochemistry design and the Public Health School, Fujian Medical University, for assistance in data processing and statistical analysis. The present study was supported by the National Natural Science Foundation of China (grant no. 21435002).

\section{References}

1. Seidel C, Dörner N, Osswald M, Wick A, Platten M, Bendszus M and Wick W: Does age matter?-A MRI study on peritumoral edema in newly diagnosed primary glioblastoma. BMC Cancer 11: 127, 2011.

2. Schoenegger K, Oberndorfer S, Wuschitz B, Struhal W, Hainfellner J, Prayer D, Heinzl H, Lahrmann H, Marosi C and Grisold W: Peritumoral edema on MRI at initial diagnosis: An independent prognostic factor for glioblastoma? Eur J Neurol 16: 874-878, 2009

3. Cheng L, Huang Z, Zhou W, Wu Q, Donnola S, Liu JK, Fang X, Sloan AE, Mao Y, Lathia JD, et al: Glioblastoma stem cells generate vascular pericytes to support vessel function and tumor growth. Cell 153: 139-152, 2013.

4. Soda Y, Myskiw C, Rommel A and Verma IM: Mechanisms of neovascularization and resistance to anti-angiogenic therapies in glioblastoma multiforme. J Mol Med (Berl) 91: 439-448, 2013.

5. Lu S, Ahn D, Johnson G, Law M, Zagzag D and Grossman RI: Diffusion-tensor MR imaging of intracranial neoplasia and associated peritumoral edema: Introduction of the tumor infiltration index. Radiology 232: 221-228, 2004.

6. Lin ZX: Glioma-related edema: New insight into molecular mechanisms and their clinical implications. Chin J Cancer 32: 49-52, 2013.

7. Hartmann M, Jansen O, Egelhof T, Forsting M, Albert FK and Sartor K: Effect of brain edema on the recurrence pattern of malignant gliomas. Radiologe 38: 948-953, 1998 (In German).

8. Engelhorn T, Savaskan NE, Schwarz MA, Kreutzer J, Meyer EP, Hahnen E, Ganslandt O, Dörfler A, Nimsky C, Buchfelder M and Eyüpoglu IY: Cellular characterization of the peritumoral edema zone in malignant brain tumors. Cancer Sci 100: 1856-1862, 2009.

9. Zhou Y, Larsen PH, Hao C and Yong VW: CXCR4 is a major chemokine receptor on glioma cells and mediates their survival. J Biol Chem 277: 49481-49487, 2002.

10. Bian XW, Yang SX, Chen JH, Ping YF, Zhou XD, Wang QL, Jiang XF, Gong W, Xiao HL, Du LL, et al: Preferential expression of chemokine receptor CXCR4 by highly malignant human gliomas and its association with poor patient survival. Neurosurgery 61: 570-579, 2007.

11. Ehtesham M, Winston JA, Kabos P and Thompson RC: CXCR4 expression mediates glioma cell invasiveness. Oncogene 25: 2801-2806, 2006.

12. Stevenson CB, Ehtesham M, McMillan KM, Valadez JG, Edgeworth ML, Price RR, Abel TW, Mapara KY and Thompson RC: CXCR4 expression is elevated in glioblastoma multiforme and correlates with an increase in intensity and extent of peritumoral T2-weighted magnetic resonance imaging signal abnormalities. Neurosurgery 63: 560-570, 2008.

13. Barbero S, Bonavia R, Bajetto A, Porcile C, Pirani P, Ravetti JL, Zona GL, Spaziante R, Florio T and Schettini G: Stromal cell-derived factor lalpha stimulates human glioblastoma cell growth through the activation of both extracellular signal-regulated kinases 1/2 and Akt. Cancer Res 63: 1969-1974, 2003.

14. Lin ZX: Patterns in the occurrence and development of tumors. Chin Med J (Engl) 124: 1097-1104, 2011.

15. Louis DN, Ohgaki H, Wiestler OD, Cavenee WK, Burger PC, Jouvet A, Scheithauer BW and Kleihues P: The 2007 WHO classification of tumours of the central nervous system. Acta Neuropathol 114: 97-109, 2007.

16. Zagzag D, Esencay M, Mendez O, Yee H, Smirnova I, Huang Y, Chiriboga L, Lukyanov E, Liu Mand Newcomb EW: Hypoxia- and vascular endothelial growth factor-induced stromal cell-derived factor-1alpha/CXCR4 expression in glioblastomas: One plausible explanation of Scherer's structures. Am J Pathol 173: 545-560, 2008.

17. Wu B, Chien EY, Mol CD, Fenalti G, Liu W, Katritch V, Abagyan R, Brooun A, Wells P, Bi FC, et al: Structures of the CXCR4 chemokine GPCR with small-molecule and cyclic peptide antagonists. Science 330: 1066-1071, 2010.

18. Yoshie O,Imai T and Nomiyama H: Novel lymphocyte-specific CC chemokines and their receptors. J Leukoc Biol 62: 634-644, 1997.

19. Furusato B, Mohamed A, Uhlén M and Rhim JS: CXCR4 and cancer. Pathol Int 60: 497-505, 2010. 
20. Sun X, Cheng G, Hao M, Zheng J, Zhou X, Zhang J, Taichman RS, Pienta KJ and Wang J: CXCL12/CXCR4/CXCR7 chemokine axis and cancer progression. Cancer Metastasis Rev 29: 709-722, 2010.

21. Hong X, Jiang F, Kalkanis SN, Zhang ZG, Zhang XP, DeCarvalho AC, Katakowski M, Bobbitt K, Mikkelsen T and Chopp M: SDF-1 and CXCR4 are up-regulated by VEGF and contribute to glioma cell invasion. Cancer Lett 236: 39-45, 2006.

22. Lu DY, Tang CH, Yeh WL, Wong KL, Lin CP, Chen YH, Lai $\mathrm{CH}$, Chen YF, Leung YM and Fu WM: SDF-1alpha up-regulates interleukin-6 through CXCR4, PI3K/Akt, ERK, and NF-kappaB-dependent pathway in microglia. Eur J Pharmacol 613: 146-154, 2009.

23. Kryczek I, Lange A, Mottram P, Alvarez X, Cheng P, Hogan M, Moons L, Wei S, Zou L, Machelon V, et al: CXCL12 and vascular endothelial growth factor synergistically induce neoangiogenesis in human ovarian cancers. Cancer Res 65: 465-472, 2005.
24. Mirshahi F, Pourtau J, Li H, Muraine M, Trochon V, Legrand E, Vannier J, Soria J, Vasse M and Soria C: SDF-1 activity on microvascular endothelial cells: Consequences on angiogenesis in in vitro and in vivo models. Thromb Res 99: 587-594, 2000.

25. Guleng B, Tateishi K, Ohta M, Kanai F, Jazag A, Ijichi H, Tanaka Y, Washida M, Morikane K, Fukushima Y, et al: Blockade of the stromal cell-derived factor-1/CXCR4 axis attenuates in vivo tumor growth by inhibiting angiogenesis in a vascular endothelial growth factor-independent manner. Cancer Res 65: 5864-5871, 2005.

26. Tachibana K, Hirota S, Iizasa H, Yoshida H, Kawabata K, Kataoka Y, Kitamura Y, Matsushima K, Yoshida N, Nishikawa S, et al: The chemokine receptor CXCR4 is essential for vascularization of the gastrointestinal tract. Nature 393: 591-594, 1998

27. Lv S, Sun B, Zhong X, Dai C, Wang W, Ma X, Song H, Shi R and Wang R: The clinical implications of chemokine receptor CXCR4 in grade and prognosis of glioma patients: A meta-analysis. Mol Neurobiol 52: 555-561, 2015. 